University of Nebraska - Lincoln

DigitalCommons@University of Nebraska - Lincoln

Nebraska Cooperative Fish \& Wildlife Research Nebraska Cooperative Fish \& Wildlife Research Unit -- Staff Publications

1999

\title{
Body Mass Patterns Predict Invasions and Extinctions in Transforming Landscapes
}

Craig R. Allen

University of Nebraska-Lincoln, callen3@unl.edu

Elizabeth A. Forys

Eckerd College

C. S. Holling

University of Florida

Follow this and additional works at: https://digitalcommons.unl.edu/ncfwrustaff

Part of the Other Environmental Sciences Commons

Allen, Craig R.; Forys, Elizabeth A.; and Holling, C. S., "Body Mass Patterns Predict Invasions and Extinctions in Transforming Landscapes" (1999). Nebraska Cooperative Fish \& Wildlife Research Unit -Staff Publications. 7.

https://digitalcommons.unl.edu/ncfwrustaff/7

This Article is brought to you for free and open access by the Nebraska Cooperative Fish \& Wildlife Research Unit at DigitalCommons@University of Nebraska - Lincoln. It has been accepted for inclusion in Nebraska Cooperative Fish \& Wildlife Research Unit -- Staff Publications by an authorized administrator of DigitalCommons@University of Nebraska - Lincoln. 


\title{
Body Mass Patterns Predict Invasions and Extinctions in Transforming Landscapes
}

\author{
Craig R. Allen, ${ }^{1 *}$ Elizabeth A. Forys, ${ }^{2}$ and C. S. Holling ${ }^{1}$
}

\begin{abstract}
${ }^{1}$ Department of Zoology, 110 Bartram Hall, University of Florida, Gainesville, Florida 32611; and 2Department of Environmental Science, 4200 54th Avenue South, Eckerd College, St. Petersburg, Florida 33711, USA
\end{abstract}

\begin{abstract}
A BStRACT
Scale-specific patterns of resource distribution on landscapes entrain attributes of resident animal communities such that species body-mass distributions are organized into distinct aggregations. Species within each aggregation respond to resources over the same range of scale. This discontinuous pattern has predictive power: invasive species and extinct or declining species in landscapes subject to human transformation tend to be located at the
\end{abstract}

edge of body-mass aggregations ( $P<0.01$ ), which may be transition zones between distinct ranges of scale. Location at scale breaks affords species great opportunity, but also potential crisis.

Key words: cross-scale; ecosystem structure; endangered species; Everglades ecosystem; extinctions; invasions.

\section{INTRODUCTION}

Landscape pattern is scale dependent ( $\mathrm{O}^{\prime} \mathrm{Neill}$ and others 1991; Milne and others 1992), and differently sized animals living upon the same landscape perceive their environment at different scales (Milne and others 1989; Holling 1992; Peterson and others 1998). Increasing evidence suggests that ecosystems are structured by relatively few key processes operating at specific temporal and spatial scales (Carpenter and Leavitt 1991; Levin 1992; Holling and others 1995). The distinct temporal frequencies and spatial scale characterizing these key processes create hierarchical landscape structures with scale-specific pattern. The scale-specific effect of key processes leads to a discontinuous distribution of ecological structure and pattern (Burrough 1981), which in turn entrains attributes of animals residing on the landscape (Holling 1992). This entrainment reflects ad-

Received 19 May 1998; accepted 24 November 1998

*Corresponding author's current address: South Carolina Cooperative Fish and Wild life Research Unit, Room G27, Lehotsky Hall, Clemson University, Clemson, South Carolina 29634, USA Corresponding author, email: Allencr@Clemson.edu aptations to a discontinuous pattern of resource distribution acting on animal community assembly and evolution both by sorting species and by providing a specific set of evolutionary opportunities and constraints. On the animal community level, this is expressed by an aggregated pattern of species body masses (Holling 1992). Animals within a particular body-mass aggregation perceive and exploit the environment at the same range of scale.

The discontinuous, aggregated pattern in animal communities may result from the interaction between key self-organizing processes, landscapes, and animals (Holling 1992; Perry 1994). Human development of landscapes changes some of the self-organizing processes so that landscape patterns begin to be transformed. If animal body-mass aggregations are linked to scale-specific structures, such perturbations should reveal themselves by changes in species turnover that affect body-mass aggregation patterns. We tested five competing hypotheses by determining whether invasive species and extinct or declining species were nonrandomly distributed in terms of vertebrate community body-mass patterns. In addition to testing those hypotheses, we 
also established that discontinuous body-mass distributions exist in ecosystems other than the boreal forest, and in taxa other than birds and mammals (Holling 1992).

\section{Methods and Analysis}

\section{Species Lists}

We used data from the Everglades ecoregion of south Florida to investigate the relationship between body-mass patterns in animal communities and biological invasions and extinctions. This region has experienced large-scale landscape transformations, and a large percent of its vertebrate fauna is threatened, declining, extinct, or nonnative. Three general vertebrate taxonomic groups were used as replicates: herpetofauna, birds, and mammals. Species distributions were determined from museum records, published accounts, and theF lorida Breeding Bird Atlas (Kale and others forthcoming). Only species that had established breeding populations in the Everglades ecoregion (Bailey 1983) were included in the analysis. Because species distributions were available at the county level, we used records from the seven southernmost Florida counties within the Everglades ecoregion. Oceanic and deep-water aquatic species were excluded from the analysis because they interact with their environment differently than do terrestrial species (Holling 1992) and may be trophically compartmentalized from terrestrial systems (Pimm and Lawton 1980).

A species was considered to be a biological invader if it became established after it was introduced to south Florida by humans or if it was a nonindigenous species that naturally expanded its range following anthropogenic landscape transformations associated with European colonization. A species was considered to be endangered if it was listed by the state of Florida (Florida Game and Freshwater Fish Commission 1994) as being extinct, endangered, threatened, or a species of special concern (hereafter, dedining species). Listed subspecies were not included unless they were the only subspecies occurring in south Florida, or if all subspecies were listed.

In most cases, data on vertebrate body masses were collected from published sources. For a portion of the herpetofauna, body mass was determined from unpublished field data or by weighing a sample $(n=10)$ of preserved museum specimens. Although some weight changes occur during the preservation process, these changes tend to be less than 10\% (Haighton 1956; Mount 1963). In all cases, adult male and female weights were averaged.
A.

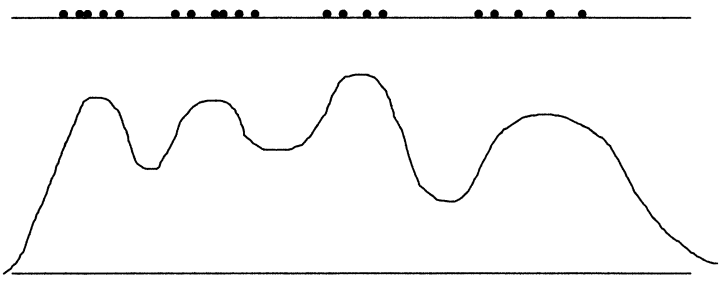

B.

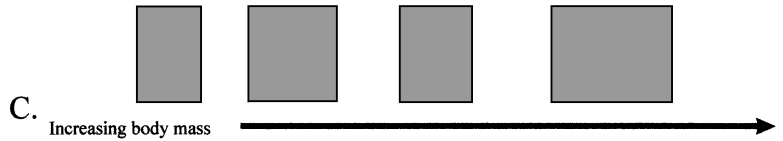

Figure 1. The rank-ordered distribution of animal body masses are discontinuous. A Location of species in a hypothetical community along a log-transformed bodymass axis. Species form distinct aggregations, separated by gaps. B Density plot of data from A. C Stylized portrayal of the body-mass pattern of the hypothetical animal community in A.

\section{Analysis}

The goals of our analysis were outwardly simple. First, we sought to determine whether body masses of the threetaxonomic groupsanalyzed were distributed discontinuously and, if so, we sought to determine where discontinuities occurred in the data (that is, determine the body-mass patterns of the preinvasion faunas). Second, we sought to determine whether invasive, and extinct and declining, species were randomly or nonrandomly distributed in relation to the body-mass pattern of each vertebrate group.

All native species within each vertebrate class (including recently extinct species) were ranked in order of body mass to determine whether discontinuities existed within the ranked distribution of the recent historical fauna (Figure 1). Invasive species were not included in the faunal list when determining body-mass patterns in order to reconstitute preinvasion communities. Body-mass distributions were analyzed by using simulations that compared actual data with a null distribution established by estimating a continuous unimodal kernal distribution of the log-transformed data (Silverman 1981). Significance of discontinuities in the data was determined by calculating the probability that the observed discontinuities were chance events by comparing observed values with the output of 1000 simulations from the null set [see Restrepo and others (1997)]. Because $n$ in our three data sets varied from 35 (mammals) to 106 (birds), and because we were most interested in determining community structure, we maintained a constant statistical power of approximately 0.50 when setting 


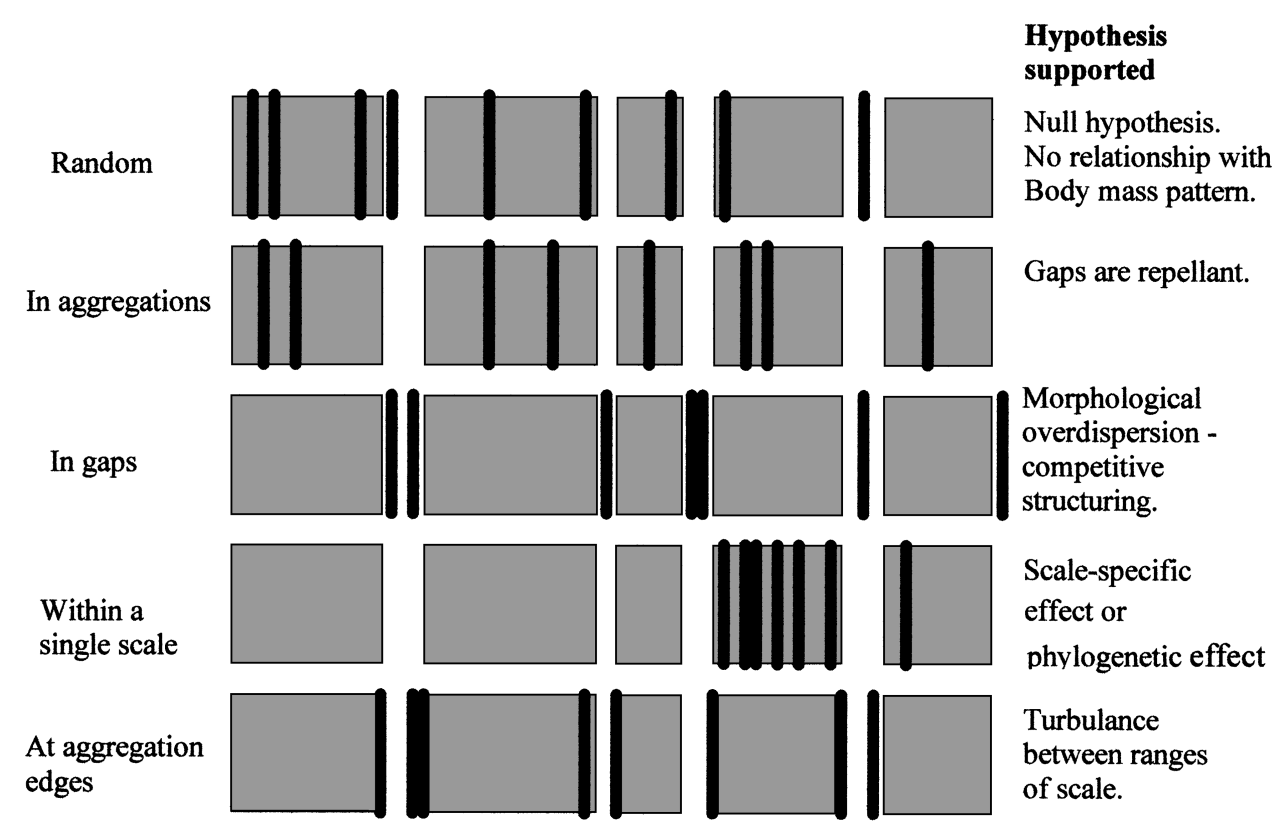

Figure 2. Possible pattern of invasions or deletions in the context of animal community body-mass structure. A different pattern, or a lack of a pattern, supports a different hypotheses.

alpha for detecting discontinuities. Although we believe that the application of a null model is the best method for determining body-mass aggregations, we confirmed our results with a form of the split moving-window boundary analysis [SMW; Webster (1978) and Ludwig and Cornelius (1987)] and hierarchical cluster analysis (SAS Institute 1985).

A gap was defined as an area between successive body masses that significantly exceeded the discontinuities generated by the continuous null distribution. A species aggregation was a grouping of three or more species with body masses not exceeding the expectation of the null distribution. Body-mass aggregations were defined by the two end-point species that defined either the upper or the lower extremes of the aggregation.

Invasive and declining species could be distributed in the body-mass patterns of the animal communities in a number of possible ways (Figure 2 ). (a) A random distribution would indicate that the scale-specific structure of animal communities was not related to invasions or declines. (b) Invasive species could be distributed only within body-mass aggregations, well separated from the gaps, which would indicate that gaps are "forbidden zones," but indicate little else. (c) Invasive and declining species could be restricted to a limited range of body masses, which would indicate that it is at the ecological scale corresponding to these species that perturbation has had its greatest impact (Morton 1990) or that phylogeny had a predominant influence. (d) Invasive species could occur only in gaps, which we would interpret as indicative of competitive processes unrelated to scale-specific animal community structure (Moulton and Pimm 1986). (e) Invasive and declin- ing species could occur at the edge of aggregations, which would indicate that the areas between distinct ranges of scale are most susceptible to changes in ecological process and landscape structure.

After determining the body-mass pattern of the historical faunas, we visually inspected the distributions for the aforementioned patterns. Adding invasive species to the extant community structure may be likened to throwing darts at the distribution and determining whether there was pattern to where the darts stuck. For endangered species, we quantified the pattern of listed species within the overall community. Chi-squared analysis was used to compare observed with expected frequencies, with taxonomic groups used as replicates.

\section{RESULTS}

The south Florida herpetofauna, bird, and mammal body-mass distributions were discontinuous. Distinct aggregations of species were detected in each taxa, by all methods. The results of simulations of the null model, SMW analysis, and cluster analysis converged. We observed 6-13 discontinuities in our datasets. In contrast, random draws of the same $n$ from a unimodal null revealed that $91 \%$ of the randomly generated datasets were unimodal or bimodal (Sendzimir 1998). Fewer than $1 \%$ had over five discontinuities. Also, mean gap size exceeded the variation inherent in mean body size $100 \%$ of the time in tested mammal datasets and $97 \%$ of the time in birds (Sendzimir 1998); that is, normal variation is unlikely to mask the gaps that we identified.

Invasive and declining species were nonrandomly distributed in relation to animal community body- 


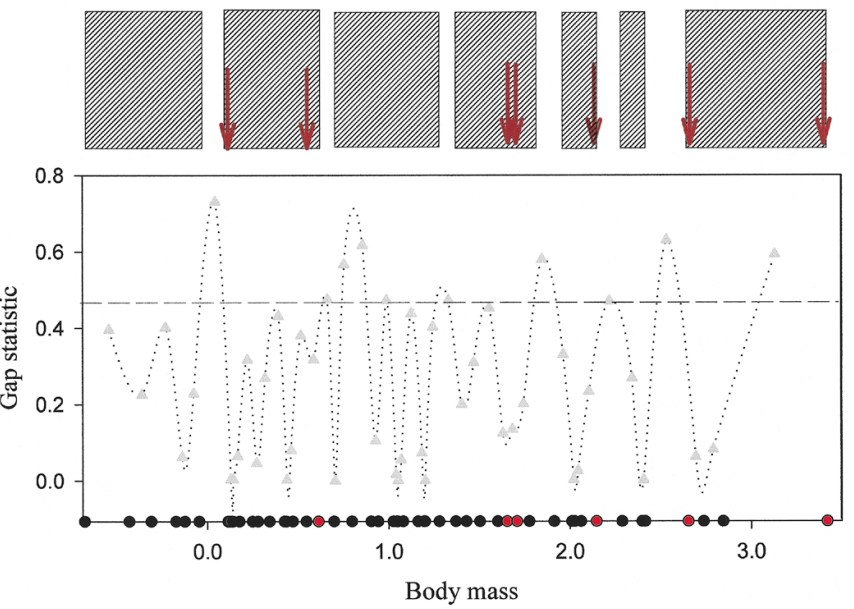

South Florida Mammals

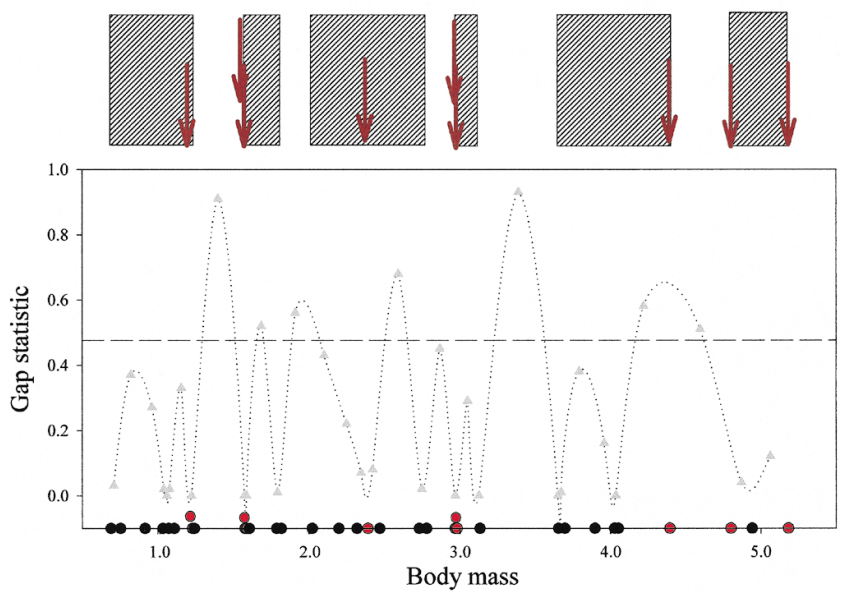

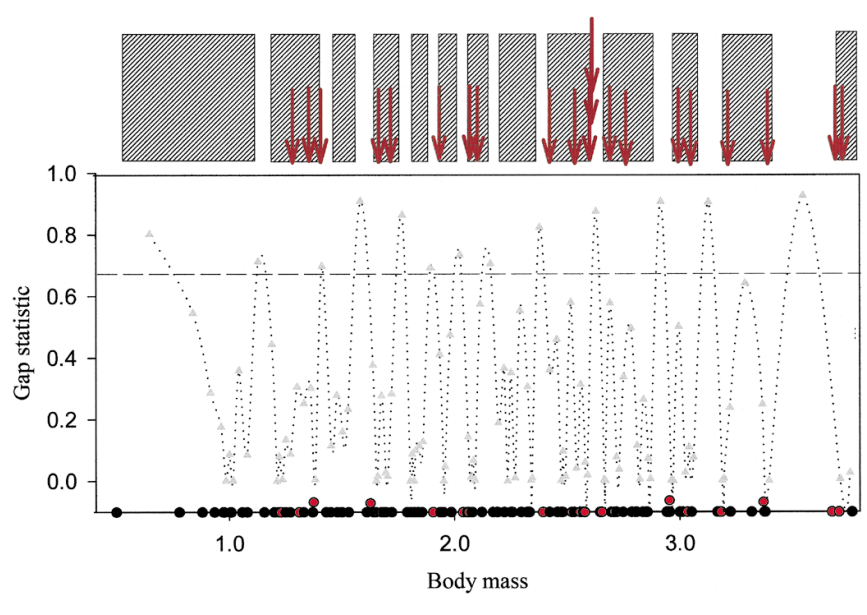

Mexican Cave Bats
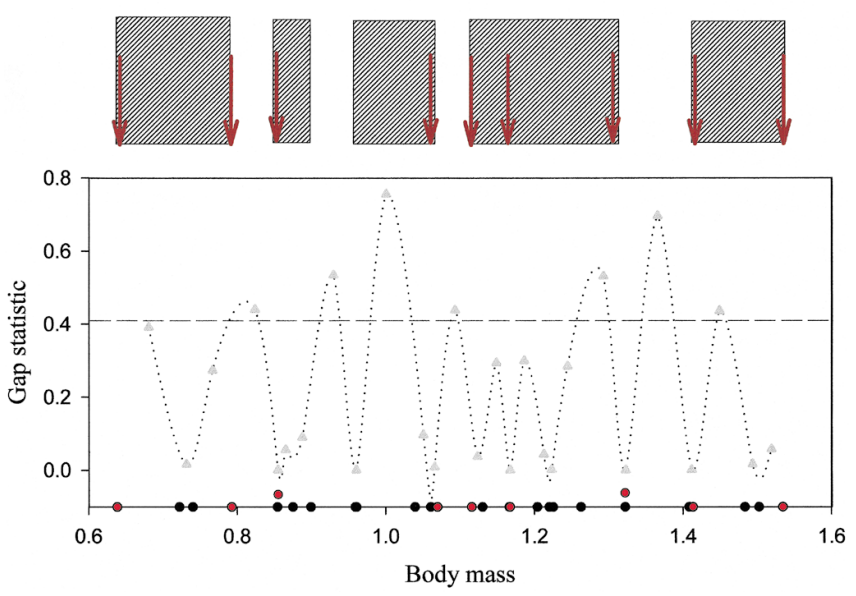

Figure 3. Gap statistic, body-mass pattern, and occurrence of listed species (red) for A Everglades herpetofauna, B birds and C mammals, and D Mexican cave bats. All data are presented in the bottom graph, whereas the top graph displays a stylized version of the body-mass pattern and location of listed species (arrows). Power for detecting gaps was kept constant, resulting in a criterion line (gap statistic, dotted line) that varied from 0.43 (bats, $n=28$ ) to 0.68 (birds, $n=106$ ). Aggregations (shaded) were defined as groups of 3 or more species bordered by significant gaps; this criteria led to us to disregard some high values of the gap statistic. Note, however, that changes in body-mass patterns due to the above make no difference in the overall patterns detected.

mass patterns. Both invasive and declining species were concentrated at the edge of aggregations for each taxonomic group (Figure 3 and Table 1). For both invasive $\left(\chi^{2}=12.94,2 \mathrm{df} ; \mathrm{P}=0.002\right)$ and declining ( $\left.\chi^{2}=8.61,2 \mathrm{df} ; \mathrm{P}=0.01\right)$ species, across all taxonomic replicates, approximately twice as many species as expected occurred at aggregation edges (Table 1). No other patterns in the data were detected. Phylogeny was not responsible for observed body-mass pattern (that is, aggregations do not tend to consist of a single family or order) or for endangered status (that is, the largest member of a family did not tend to be listed). Other traditional, simple, single species-based hypotheses were not supported (Forys and Allen 1998).

Three additional analyses confirmed those conclusions. First, to provide an alternative analysis of our invasion data, we used the same data for successful invasive bird species in the Everglades, but also incorporated unsuccessful invaders to test the prediction that the body masses of unsuccessful invaders were not associated with aggregation edges. We eliminated the effect of small propagule size by including only those species that were known to have been introduced as multiples, known or suspected to have bred, and persisted for at least 5 
Table 1. Location of Endangered, Declining, and Invasive Species in the Everglades Ecosystem Vertebrate Fauna in Terms of Body Mass Pattern

\begin{tabular}{|c|c|c|c|c|c|c|c|}
\hline & \multirow{3}{*}{$\begin{array}{l}\text { Native } \\
n\end{array}$} & \multicolumn{3}{|c|}{ Listed } & \multicolumn{3}{|c|}{ Invasive } \\
\hline & & \multicolumn{3}{|c|}{ at edge $(\%)$} & \multicolumn{3}{|c|}{ at edge (\%) } \\
\hline & & $n$ & obs & exp. & $\mathrm{n}$ & obs & $\exp$ \\
\hline Herpetofauna & 50 & 7 & 57 & 28 & 21 & 29 & 16 \\
\hline Avifauna & 106 & 21 & 38 & 24 & 36 & 25 & 13 \\
\hline Mammals & 35 & 9 & 78 & 34 & 11 & 55 & 19 \\
\hline \multicolumn{8}{|l|}{$\begin{array}{c}\text { Average \% } \\
\text { at scale } \\
\text { breaks }\end{array}$} \\
\hline (exp) & & & 58 & 29 & & 36 & 16 \\
\hline
\end{tabular}

A large percentage (obs) of both dedining and invasive species occur at the edge of body mass aggregations. Expected (exp, as a percent) dedining and invasive fauna occurring at aggregation edges are given in brackets.

years. This conservative cut yielded data for 36 successful introductions and invasions and 46 unsuccessful introductions. We then compared the distributions of distances to body-mass aggregation edges (distances were determined by calculating the distance of all species, in log body-mass terms, to the nearest body-mass-edge defining species) between the successful and unsuccessful groups. The distance to aggregation edge for successful species was significantly less than for unsuccessful species (Mann-Whitney rank-sum test, $\mathrm{T}=1217.5$ and $\mathrm{P}=$ 0.027).

As an additional independent test of endangered species association with aggregation edges, we analyzed the cave bats of Mexico. The main caveroosting bats of M exico comprise 28 species, nine of which have been categorized as fragile or vulnerable (Arita-Watanabe 1992). Seven of the nine species categorized as fragile or vulnerable had body masses located at the edge of body-mass aggregations (Figure 3D). If that distribution was random, we would have expected fewer than four fragile or vulnerable species to occur at aggregation edges. The distance to aggregation edge for fragile or vulnerable species was significantly less than for the other native species ( $M$ ann-Whitney rank sum test, $T=85.0$ and $\mathrm{P}=0.014)$.

As an independent test of invasive species association with aggregation edges, we also analyzed the birds and mammals from Mediterranean-climate Australia. There are 141 native bird species associated with the Mediterranean ecotype of southwestern Australia (Schodde 1981) and 31 native mammals in the Mediterranean ecotype of south-central Australia (Strahan 1995). Nine nonindigenous birds and 10 mammals have established successfully in those regions. Four times as many nonindigenous birds were found at aggregation edges than would be expected by chance, and three times as many mammals, accounting for $50 \%$ of the invasions in both cases. Again, our previous results were confirmed: in transforming landscapes, both endangered and invasive species have body masses close to the edge of body-mass aggregations.

\section{Discussion}

Discontinuous body-mass distributions were found in all ecosystems and taxa that we examined. Such discontinuous or "lumpy" distributions also have been demonstrated for boreal region mammals and birds (Holling 1992), for tropical forest birds (Restrepo and others 1997), and for pre- and postextinction Pleistocene mammal faunas (Lambert and Holling 1998). The present analysis extends that conclusion to include animal communities in additional ecotypes (Everglades wet savanna and Australian Mediterranean) and taxa (herpetofauna and bats).

Although we are discovering that discontinuous patterns in body-mass distributions seem ubiquitous, it is easy to ignore them. They represent patterns of departure of body masses from some central tendency that typically is represented by a simple continuous distribution. Traditional approaches seek a unimodal distribution that best describes the data [for example, see May (1978) and Schoener and J ansen (1968) ], and the residuals are ignored. It is the patterns of residuals around such a unimodal distribution that form the "lumps" or aggregations of similar body masses. As a result, traditional statistical tests designed to minimize type I error can miss identifying real aggregations. Manly (1996), for example, applied an elegant but particularly conservative test to the original boreal animal datasets [in Holling (1992)], and concluded that, at the most, two lumps or aggregations of body masses were significant, rather than the eight and more that Holling identified. The data presented here similarly would show few or no significant aggregations by using such a conservative method.

Conservative tests, of course, reduce the chance of being wrong (type I error) - but they also reduce the ability to detect real pattern. If that is done too early in an investigation, potentials for novel discovery are sharply reduced. Hence, in the tests of discontinuities presented here, we attempt to minimize, initially, type II error; that is, to reduce the chance of missing a real pattern. That sets the stage for a sequence of tests of increasing breadth and 
rigor in order to develop multiple lines of evidence that might converge on a robust demonstration and explanation.

In this case, we are following four steps to prove and expand the concept:

1. Tests for pattern in distributions using tests that, initially, minimize type II error. These focus on examining patterns of residuals - that is, on sequences of departures from a unimodal null distribution-but it is easy to miss the pattern. For example, tests of probabilities of individual departures of various degrees from a null distribution alone are inappropriate, because they ignore the pattern caused by sequences of departures. Similarly, tests using uniform distributions as a null, as is common in the community ecology literature, are inadequate because such distributions create false body-mass gaps when fitted to distributions that have (as these do) a prominent mode or modes. The Silverman (1981) kernal-density-estimate method, as used here, is an excellent way to identify an unbiased unimodal null distribution.

2. Expanding the comparative evidence. There is a need for evidence of discontinuous patterns revealed by using the same objective methods in different ecotypes, different taxa, and for different attributes. So far, there is evidence published for body-mass data from boreal prairies, boreal forests, wet savannas, tropical lowland and highland forests, and Mediterranean-type ecosystems; and for birds, mammals, herpetofauna, and bats.

3. Establishing causation. Competing hypotheses for explaining pattern need to be established and multiple sets of different data used to separate among the hypotheses. Body-mass aggregations and the gaps between them could be caused by founder effects, by phenological organization, by trophic or competitive interrelations, by locomotory constraints, and/or by entrainment to landscape/ vegetation patterns. A number of causes are likely, but evidence so far converges on the latter as a dominating explanation [here and see Holling (1992)].

4. Relating to existing theory. The original idea came from a set of regional ecosystem studies [summarized in Holling (1992)] where hierarchy theory (Allen and Starr 1982; O'Neill and others 1986) combined with theories of ecosystem dynamics (Carpenter and Leavitt 1991; Levin 1992; Holling and others 1995) led to the proposition that ecosystem and animal community attributes should be distributed discontinuously across scales in time and space.

5. Developing independent datasets to test causation. Strong tests that minimize type I error begin to be appropriate when entirely independent datasets are compared. Examples include comparison of bodymass patterns in similar and dissimilar ecotypes on different continents, or of patterns in different taxa or trophic groups in the same ecosystem. This report presents one of the strongest tests to date. The animal body-mass data presented here are entirely independent of the datasets designating endangered and invasive species. The body-mass aggregations and gaps between them are identified by the methods in step 1, where type II error is minimized. The body-mass aggregations and gaps so identified show unambiguously that more endangered and invasive species exist at or near the edge of the body-mass lumps than could be expected by chance alone. This is consistently the case for four different taxa (birds, mammals, herpetofauna, and bats) in three different ecotypes.

In short, body-mass aggregations identified with the methods used here are powerful predictors of endangerment and invasiveness in transforming landscapes. If we could demonstrate that the relationship breaks down, over some scale ranges, in stable landscapes, the test would be even more convincing. Unfortunately, it is difficult to find convincing examples of ecosystems and landscapes that are not transformed by human activity.

The strong correspondence between the independent attributes of population status and body-mass pattern in three different taxa confirms the existence of discontinuous body-mass distributions. It may seem initially surprising that both invasive and declining species are located at the edge of bodymass aggregations. These results suggest that something similar must be shared by the two extreme biological conditions represented by invasive species and declining species.

Note that our investigation has used definitions of endangerment and decline derived by an administrative process of government. Such definitions are conservative and tend to lag behind actual fluctuations in animal populations. For invasive species, historical contingency has played a large role in introductions. For instance, small animals such as mice and rats often are inadvertently transported, but antelope have likely never been stowaways on a ship or plane. It is not useful to describe historical happenstance; rather, the relevant question is, given that a number of species are introduced, which will succeed? We believe that the scale of environmental use by a species and landscape-level ecological transformation are important in predicting species' success or failure.

We hypothesize that the expected results of disturbance that exceeds the resilience of an ecological 


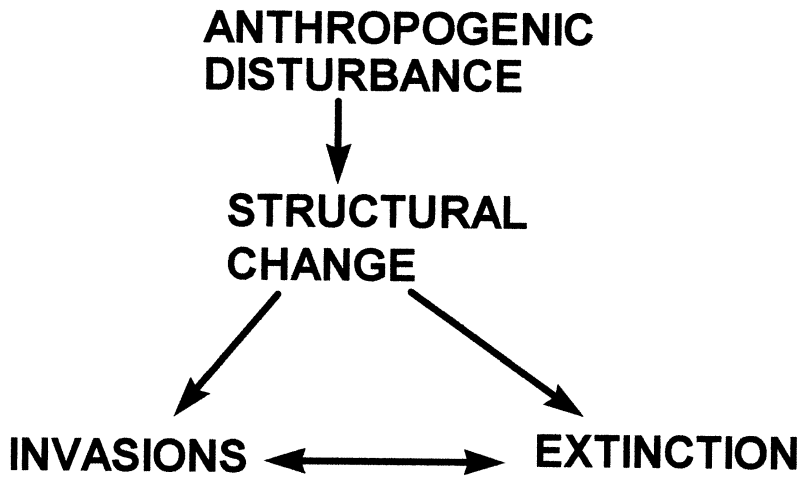

Figure 4. The relationship between disturbance, ecological structure, invasions, and extinctions. Disturbance exceeding the resilience of a system affects ecological structure, which in turn leads to changes in animal communities. Additionally, changes in animal community membership may in turn lead to further changes: invasions, especially by predators, may lead to further declines in native species (Simberloff 1981), and extinctions may lead to further invasions (Diamond and Veitch 1981).

system (Holling 1973) are simultaneous events of invasion and deletion (Figure 4). Intense or extensive anthropogenic disturbance and land-use change may exceed the resilience of a system, disrupting the key processes that structure ecosystems and entrain biotic variables. When the resilience of a system is exceeded, new processes begin to control the system, and landscape structure proceeds through a transition to a new dynamic stable state. Because animal communities in an ecosystem are entrained by ecological structure, perturbation affects the structure of animal communities. Changes in key processes cause a transition from one type of self-organizing landscape structure to another. This results in changes in the animal community, including successful invasions and the decline or extinction of susceptible native species. Species with body masses near aggregation edges are the first to encounter changes occurring as landscape patterns start to transform.

At a global scale, rapid anthropogenic disturbance is affecting the processes that structure most ecosystems. Feedback from variables adapted to the altered ecosystem structure (for example, invasive species) prevents return to the original state. As more invasive species become established, they may further alter the environment and promote or entrench structural change. In south Florida, continuing invasions and declines in native species indicate that the community is still in a state of flux, responding to changes in landscape structures that lag behind changes in disturbance regimes. Even if original key processes are reestablished, the original animal community is not likely to be reassembled (Case 1990; Drake and others 1996).

Unusual characteristics are associated with the edge of body-mass aggregations. The edges of aggregations may be considered zones of crisis and opportunity, depending on the way a given species at these scales exploits resources and interacts with its environment, and may be analogous to phase transitions. In perturbed systems, we documented that biological invasions and extinctions tend to occur at aggregation edges. However, wesuspect that variability in species composition and population status is higher at scale breaks (the edge of body-mass aggregations) whether or not the system has been perturbed. Human landscape transformations simply heighten the inherent variability. Highly variable behavior such as this has been demonstrated for the area between domains of scale in physical systems (Nittmann and others 1985; O'Neill and others 1986; Grebogi and others 1987) and postulated for biological communities (Wiens 1989). This investigation is the first to document unusual characteristics associated with scale breaks in animal communities.

\section{ACKNOWLEDGM ENTS}

We thank P. Marples, J. Sendzemir, and other colleagues in the Arthur Marshall Ecology Lab for adding to the conceptual foundation upon which this article was based. We thank D. Auth for providing access to the Florida Museum of Natural History herpetological collection, and K. Dodd for providing unpublished data on herpetofauna body mass. The manuscript was improved by comments from $\mathrm{T}$. Allen, L. Gunderson, M. Moulton, G. Peterson, and an anonymous reviewer. This work was partially supported by a NASA/EOS grant and a NASA grant.

\section{REFERENCES}

Allen TFH, Starr TB. 1982. Hierarchy: perspectives for ecological complexity. Chicago: University of Chicago Press.

Arita-Watanabe H. 1992. Ecology and conservation of cave bat communities in Yucatan, Mexico [PhD dissertation]. Gainesville: University of Florida.

Bailey RG. 1983. Delineation of ecosystem regions. Environ Manage 7:365-73.

Burrough PA. 1981. Fractal dimensions of landscapes and other environmental data. Nature 294:240-2.

Carpenter SR, Leavitt PR. 1991. Temporal variation in paleolimnological record arising from a trophic cascade. Ecology 72: 277-85.

Case TJ . 1990. Invasion resistance arises in strongly interacting species-rich model competition communities. Proc Natl Acad Sci USA 87:9610-4. 
Diamond J M, Veitch CR. 1981. Extinctions and introductions in the New Zealand avifauna: cause and effect? Science 211:499501.

Drake J A, Huxel GR, Hewitt CL. 1996. Microcosms as models for generating and testing community theory. Ecology 77:670-7.

Florida Game and Freshwater Fish Commission. 1994. Official lists of endangered and potentially endangered fauna and flora in Florida. Tallahassee: Florida Game and Freshwater Fish Commission.

Forys EA, Allen CR. 1998. Biological invasions and deletions: community change in south Florida. Biol Conserv 87:341-347.

Grebogi C, Ott E, Yorke J A. 1987. Chaos, strange attractors, and fractal basin boundaries in nonlinear dynamics. Science 238 : 632-8.

Haighton R. 1956. The life history of the slimy salamander, Plethodon glutinosus, in Florida. Copeia 1956:75-93.

Holling CS. 1973. Resilience and the stability of ecological systems. Annu Rev Ecol Syst 4:1-23.

Holling CS. 1992. Cross-scale morphology, geometry, and dynamics of ecosystems Ecol M onogr 62:447-502.

Holling CS, Schindler DW, Walker BW, Roughgarden J. 1995. Biodiversity in the functioning of ecosystems: an ecological synthesis. In: Perringsc, Mäler CKG, Folke C, Holling CS, J ansson BO, editors. Biodiversity loss: economic and ecological issues. New York: Cambridge University Press. p 44-83.

Kale HW II, Pranty B, Stith BM, Biggs CW. The atlas of the breeding birds of Florida. Forthcoming.

Lambert WD, Holling CS. 1998. Causes of ecosystem transformation at the end of the Pleistocene: evidence from mammal body-mass distributions. Ecosystems 1:157-75.

Levin SA. 1992. The problem of pattern and scale in ecology. Ecology 73:1943-67.

Ludwig J A, Cornelius J M. 1987. Locating discontinuities along ecological gradients. Ecology 68:448-50.

Manly BF. 1996. Are there clumps in body-size distributions. Ecology 77:81-6.

May RM. 1978. The dynamics and diversity of insect faunas. In: Mound LA, Waloff $N$, editors. Diversity of insect faunas. Oxford: Blackwell Scientific. p 188-204.

Milne BT, J ohnston K, Forman RTT. 1989. Scale dependent proximity of wildlife habitat in a spatially-neutral Bayesian model. Landscape Ecol 2:101-10.

Milne BT, Turner MG, Wiens J A, J ohnson AR. 1992. Interactions between the fractal geometry of landscapes and allometric herbivory. Theor Popul Biol 41:337-53.

Morton SR. 1990. The impact of European settlement on the vertebrate animals of arid Australia: a conceptual model. Proc Ecol Soc Aust 16:201-13.

Moulton MP, Pimm SL. 1986. The extent of competition in shaping an introduced avifauna. In: Diamond J, Case TJ, editors. Community ecology. New York: Harper and Row. $p$ 80-97.

Mount RH. 1963. The natural history of the red-tailed skink (Eumeces egregius Baird). Am Midl Nat 70:356-85.

Nittmann J, Daccord G, Stanley HE. 1985. Fractal growth of viscous fingers: quantitative characterization of a fluid instability phenomenon. Nature 314:141-4.

O'Neill RV, DeAngelis DL, Waide JB, Allen TFH. 1986. A hierarchical concept of ecosystems. Princeton: Princeton University Press.

O'Neill RV, Turner SJ , Cullinam VI, Coffin DP, Cook T, Conley W, Brunt J, Thomas JM, Conley MR, Gosz J. 1991. Multiple landscape scales: an intersite comparison. Landscape Ecol 5:137-44.

Perry DA. 1994. Self-organizing systems across scales. Trends Ecol Evol 10:241-4.

Peterson G, Allen CR, Holling CS. 1998. Ecological resilience, biodiversity and scale. Ecosystems 1:6-18.

Pimm SL, Lawton JH. 1980. Are food webs compartmented? J Anim Ecol 49:879-98.

Restrepo C, Renjifo LM, Marples P. 1997. Frugivorous birds in fragmented neotropical montane forests: landscape pattern and body mass distribution. In: Laurance WF, Bierregaard RO, editors. Tropical forest remnants: ecology, management and conservation of fragmented communities. Chicago: University of Chicago Press. p 171-89.

SAS Institute Inc. 1985. SAS user's guide: statistics. Cary (NC): SAS Institute.

Schodde R. 1981. Bird communities of the Australian mallee: composition, derivation, distribution, structure and seasonal cycles. In: di Castri F, Goodall DW, Specht RL, editors. M editerranean-type shrublands. New York: Elsevier Scientific. p 387415.

Schoener TW, J ansen DH. 1968. Notes on environmental determinants of tropical versus temperate insect size patterns. Am Nat 102:207-24.

Sendzimir J . 1998. Patterns of animal size and landscape complexity: correspondence within and across scales [PhD dissertation]. Gainesville: University of Florida.

Silverman BW. 1981. Using kernel density estimates to investigate multimodality. J R Stat Soc [B] 43:97-9.

Simberloff D. 1981. Community effects of introduced species. In: Nitecki $\mathrm{MH}$, editor. Biotic crisis in ecological and evolutionary time. New York: Academic Press. pp 53-81.

Strahan R. 1995. Mammals of Australia. Washington (DC): Smithsonian Institution Press. p 53-81.

Webster R. 1978. Optimally partitioning soil transects. J Soil Sci 29:388-402.

Wiens J A. 1989. Spatial scaling in ecology. Funct Ecol 3:385-97. 